\title{
Uma análise empírica do modelo de gestão praticado em Unidade de Conservação de Uso Sustentável
}

\author{
An empirical analysis of the management model practiced in Protected \\ Areas of Sustainable Use
}

\author{
Letyssia Maynarth de Oliveira Soares ${ }^{1}$ \\ George Emmanuel Cavalcanti de Miranda ${ }^{2}$ \\ José da Silva Mourão ${ }^{3}$
}

\begin{abstract}
Palavras-chave
Gestão participativa

Unidade de conservação

Percepção Ambiental

Resumo

O sucesso das unidades de conservação (UC) depende do tipo de governança praticada e do estabelecimento dos instrumentos de gestão ambiental. A gestão das unidades de conservação no Brasil deve ser de cunho participativo e compartilhado, no entanto seu exercício vem se mostrando um desafio para os órgãos ambientais. Assim, este artigo teve por objetivo geral apresentar a percepção dos representantes do conselho gestor sobre o modelo de gestão praticado na Área de Relevante Interesse Ecológico (ARIE) Manguezais da Foz do Rio Mamanguape/PB e da Área de Proteção Ambiental (APA) da Barra do Rio Mamanguape/PB. Por ser uma pesquisa de natureza qualitativa, optou-se pela utilização de métodos de observação participante e entrevista semiestruturada. Os sujeitos da pesquisa são os representantes do conselho consultivo da APA/ARIE Manguezais da Foz Mamanguape. Os resultados revelaram uma gestão participativa, embora o conselho seja caracterizado como imaturo, sem identidade, desorganizado e, por vezes, egocêntrico, resultado da baixa participação e coesão do grupo. Dentre outros fatores que impedem o exercício da gestão participativa e compartilhada nas UC, a análise demonstrou a baixa participação dos conselheiros nas reuniões e assembleias, o comportamento centralizador por parte dos representantes do ICMBIO, assim como múltiplos interesses e relações de poder existentes no grupo.
\end{abstract}

\section{Keywords:}

Participative management

Protected Area

Environmental perception

\begin{abstract}
The success of Protected Areas (PA) depends on the type of governance practiced and the establishment of environmental management instruments. The management of CUs in Brazil is supposed to be participative and shared, but its execution is a challenge for environmental agencies. Therefore, the main purpose of this paper
\end{abstract}

\footnotetext{
${ }^{1}$ Universidade Federal da Paraíba - UFPB, Campus I, Cidade Universitária. S/N. Castelo Branco. 58051-90 João Pessoa, PB. letyssiasoares@gmail.com

2 Universidade Federal da Paraíba - UFPB, Campus I, Cidade Universitária. S/N. Castelo Branco. 58051-90 João Pessoa, PB. miranda@dse.ufpb.br

${ }^{3}$ Universidade Estadual da Paraíba - UEPB, Campus I, R. Baraúnas, 351. Universitário. 58429-500. Campina Grande, PB. tramataia@gmail.com
} 
was to present the perception of the management councils about the management model practiced in the Area of Relevant Ecological Interest (ARIE, in Portuguese) "Manguezais da Foz do Rio Mamanguape/PB" and the Environmental Protection Area (APA, in Portuguese) of "Barra do Rio Mamanguape/PB". Characterized as a qualitative research, the methodological instruments included participant observation techniques and semi-structured interviews. The investigation subjects were the representatives of the management council of the APA/ARIE. The results revealed a legally participative management, although the council is described as immature, without identity, messed up, and, occasionally, egocentric, because of the low representativeness and cohesion of the group. Among other factors that hinder the execution of a participative and shared management model in the PA, the analysis showed a low councilor's participation in meetings and assemblies, also a centralizing behavior of the ICMBIO (institution responsible for managing the protected area), as well as multiple interests and power relations that exist in the group.

\section{INTRODUÇÃO}

A participação política da sociedade civil no Brasil mostra-se como uma estrutura débil, em razão do contexto histórico em que a sociedade foi submetida desde o processo de colonização. A reconstrução da democracia no Brasil foi caracterizada pela promulgação da Constituição de 1988, momento este caracterizado pelo surgimento de espaços públicos de tomadas de decisão e de consultas públicas, assim como pelo surgimento das associações comunitárias (QUADROS et al., 2015).

As políticas públicas brasileiras, tal como as políticas ambientais, foram pensadas e criadas em um cenário marcado pelo papel controlador do estado e pelo exercício de um modelo político autoritário e burocrático (CÂMARA, 2013) no qual os primeiros instrumentos de gestão ambiental não asseguravam a participação da sociedade civil nas tomadas de decisão, a exemplo do Código Florestal (1934 e 1965), Código de caça e pesca (1934), Decreto de proteção dos animais (1934), Código das águas (1934, 1935 e 1938), Parque Nacional (1937), Proteção ao patrimônio histórico e artístico nacional (1937), Código de Minas (1940) e Código das águas minerais (1945).

A descentralização da gestão dos recursos ambientais teve significativos avanços a partir da institucionalização da Política Nacional de Meio Ambiente (PNMA - lei n 6938/1981), que introduz a gestão participativa e da publicação da Constituição de 1988, que eleva os municípios a unidades federativas e compartilha o dever de defender e preservar os recursos ambientais, entre poder público e sociedade civil, conforme art. 225 da citada constituição.

As mudanças na formulação das políticas públicas no Brasil só foram possíveis devido as seguintes razões: os movimentos sociais ocorridos na década de 1960 e 1970, em virtude da degradação ambiental e dos desastres ambientais que vinham afetando negativamente a saúde pública; a evolução da política internacional; os problemas econômicos, sociais e ambientais que emergiram no Brasil em virtude dos modelos econômicos que foram adotados no país (CÂMARA, 2013) e; a democratização dos assuntos relacionados aos recursos ambientais, que refletiu no processo de criação e implantação das Unidades de Conservação (UC).

O acontecimento da conferência Rio 92 trouxe efeitos positivos na participação da sociedade civil na gestão dos recursos ambientais, com a institucionalização de instâncias e esferas de consultas públicas e de tomadas de decisão, como conselhos, comitês de bacia, dentre outros espaços coletivos (QUADROS et al., 2015), embora a participação popular na criação e gestão das UC tenha se consolidado apenas com a publicação do Sistema Nacional de Unidade de conservação (SNUC) (BRASIL, 2000).

O SNUC além de assegurar "a participação efetiva das populações locais na criação, implantação e gestão das unidades de conservação", determina a criação de conselhos gestores, de caráter consultivo ou deliberativo, que serão presididos "pelo órgão responsável por sua administração e constituído por representantes de órgãos públicos, de organizações da sociedade civil e das populações tradicionais residentes na área" (BRASIL, 2000, Art.29). 
O conselho gestor pode ser entendido como uma ferramenta facilitadora e fortalecedora da gestão democrática, integrada e participativa das UC (JACOBI, 2003), por ter a capacidade de potencializar o diálogo entre todos os envolvidos de forma transparente e igualitária (MAGALHÃES et al., 2010). Essa instância, do mesmo modo que assegura a representação dos envolvidos na gestão das áreas protegidas, busca o equilíbrio e equidade nas respostas das demandas sociais, bem como, tem o poder de desenvolver a consciência ambiental do grupo e provocar mudanças comportamentais, como demonstra Quadros et al. (2015) em seus estudos.

Apesar dos conselhos terem uma função tão nobre, Câmara (2013) e Magalhães et al. (2010) perceberam que muitos conselhos têm sua natureza instável em razão da baixa representatividade da sociedade civil nas grandes discussões e formulação das políticas públicas, em função do comportamento imperioso do poder público, muito embora existam estratégias destinadas ao fortalecimento da participação da sociedade civil em tais instâncias e a descentralização do poder das instituições governamentais.

Segundo Scardua e Bursztyn (2003), a descentralização não se fundamenta apenas na mudança comportamental e ideológica das instituições públicas, ela também deve dispor da solidariedade e da participação da sociedade civil, de forma que os usuários e comunitários locais tenham responsabilidade e controle sobre os recursos ambientais.

Tendo em vista a estrutura frágil dos conselhos gestores, o presente artigo tem como objetivo geral, apresentar a percepção dos representantes do conselho consultivo da Área de Preservação Ambiental da Barra do Rio Mamanguape (APA) e Área de Relevante Interesse Ecológico Manguezais da Foz do Rio Mamanguape (ARIE), áreas protegidas localizadas no litoral norte do estado da Paraíba, sobre o modelo de gestão praticado nas UC.

A realização do referido estudo justifica-se pela necessidade de compreender as complexidades no âmbito do conselho consultivo, avaliar a gestão e a participação e representatividade do grupo de conselheiros e o modelo de gestão praticado nas UC.

\section{PROCEDIMENTOS METODOLÓGICOS}

Área de estudo
A APA da Barra do Rio Mamanguape, foi criada em de 10 de setembro de 1993, através do Decreto Federal $\mathrm{n}^{\circ}$ 924. Localizada na porção norte do estado da Paraíba, entre os municípios de Rio Tinto, Lucena, Marcação e Baia da Traição, a referida UC detém uma extensão territorial de 14.640 hectares, abrangendo o território continental, estuarino e marinho.

A ARIE Manguezais da Foz do Rio Mamanguape teve sua criação em 05 de novembro de 1985 , por meio do decreto $\mathrm{n}^{\circ} 91.890$. Detentora de uma área de 5.721,07 hectares, a ARIE está localizada no interior da APA da Barra do Rio Mamanguape, na porção pertencente ao município de Rio Tinto/PB, se detendo apenas as áreas de mangue e estuário.

O bioma da região é do tipo Marinho costeiro, compreendendo os ecossistemas de duna, mata de restinga e de tabuleiro (Figura 3), bem como por corais e por uma extensa área de manguezal (ICMBIO, 2014). Dentre a diversidade faunística local, encontram-se uma variedade de espécies de peixes, crustáceos, moluscos, mamíferos aquáticos e terrestres, assim como insetos, répteis e pássaros (ICMBIO, 2014).

As atividades econômicas praticadas na APA/ARIE Manguezais da Foz do Rio Mamanguape, baseiam-se no turismo e na pesca dos recursos estuarinos e marinhos, como crustáceos (caranguejo, siri e camarão), moluscos (ostra, marisco, taioba e sururu) e variados espécimes da ictiofauna. Na região da APA da Barra do Rio Mamanguape a economia também gira em torno da agricultura familiar, produção de cana-de-açúcar e da carcinicultura e/ou piscicultura (ICMBIO, 2014).

\section{Metodologia}

A pesquisa tem caráter qualitativo, uma vez que se trabalhou com o universo dos significados, dos motivos, das aspirações, das crenças, dos valores e das atitudes (MINAYO; GOMES, 2011). Para melhor compreender e interpretar a realidade local fez-se uso das técnicas observação participante e entrevista semiestruturada.

Os sujeitos da pesquisa são os representantes do Conselho consultivo da APA da Barra do Rio Mamanguape e ARIE Manguezais da Foz do Rio Mamanguape, que é composto por 27 representantes titulares, dos quais 15 compõem o seguimento governamental (Tabela 1) e 12 do seguimento sociedade civil (Tabela 2). Dos 27 representantes participaram apenas 18 conselheiros. 
Tabela 1 Lista dos representantes que compõem o seguimento Governamental

\section{SEGUIMENTO GOVERNAMENTAL}

\section{REPRESENTANTES}

Instituto Chico Mendes de Conservação da Biodiversidade (chefia da Unidade de conservação);

Prefeitura Municipal de Rio Tinto/PB - uma vaga (titular e suplente);

Prefeitura Municipal de Lucena/PB - uma vaga (titular e suplente);

Prefeitura Municipal de Baia da Traição/PB - uma vaga (titular e suplente);

Prefeitura Municipal de Marcação/PB - uma vaga (titular e suplente);

Poder Legislativo, representado pela Câmara de Vereadores de Rio Tinto (titular) e pela Câmara de

Vereadores de Marcação (suplente) - uma vaga (titular e suplente);

Superintendência de Administração do Meio Ambiente do Estado da Paraíba / SUDEMA - uma vaga (titular e suplente);

Fundação Nacional do índio - FUNAI - uma vaga (titular e suplente);

Empresa de Assistência Técnica e Extensão Rural - EMATER - uma vaga (titular e suplente);

Secretaria de Estado de Turismo e Desenvolvimento Econômico do Estado da Paraíba - uma vaga (titular e suplente);

Agência Executiva de Gestão das Águas do Estado da Paraíba - AESA - uma vaga (titular e suplente);

Secretaria do Patrimônio da União - SPU/PB

Instituto Nacional de Colonização e Reforma Agrária - INCRA - uma vaga (titular e suplente);

Universidade Federal da Paraíba - UFPB - Titular/Universidade Estadual da Paraíba - UEPB -

Suplente

Centro de Mamíferos Aquáticos - CMA/ICMBIO - uma vaga (titular e suplente)

Org.: do Autor, 2017.

Tabela 2 Lista de representantes do seguimento Sociedade civil

\section{SEGUIMENTO USUÁRIO/ SOCIEDADE CIVIL REPRESENTANTES}

Colônia de Pescadores Z-13 (titular) e Colônia de Pescadores Z-14 (suplente);

Associação Paraibana de Carciniculturas e Piscicultores - uma vaga (titular e suplente);

Setor turístico local

Setor das Organizações Não Governamentais Socioambientais, representadas pela Fundação Mamíferos Aquáticos - FMA (titular) e ONG Guajirú (suplente) - uma vaga (titular e suplente)

Comitê de Bacias Hidrográficas do Litoral Norte da Paraíba - uma vaga (titular e suplente)

Organização Não Governamental Sociocultural -uma vaga (titular e suplente);

Associação dos Agricultores de Praia de Campina (Rep. dos Moradores da APA) - uma vaga (titular e suplente)

Representante dos índios da Terra Indígena Potiguara/PB - uma vaga (titular e suplente

Sindicato dos Produtores de Álcool e Açúcar do Estado da Paraíba - uma vaga (titular e suplente

Sindicato dos Trabalhadores Rurais do Município de Rio Tinto - uma vaga (titular e suplente

Serviço de Apoio às Micro e Pequenas Empresas da Paraíba - SEBRAE / PB - uma vaga (titular e suplente

Serviço Nacional de Aprendizagem Rural - SENAR (titular), e a Federação da Agricultura e Pecuária da Paraíba - FAEPA (suplente) - uma vaga (titular e suplente

Org.: do Autor, 2017.

A entrevista foi semiestruturada e norteada pela coleta de depoimentos formais e informais (com ou sem gravador) com o auxílio de um roteiro. Quando o uso do gravador não era consentido, foi utilizado o diário de campo para registrar as falas mais importantes dos entrevistados. As entrevistas foram realizadas individualmente com cada sujeito da pesquisa e 
ocorreram nas residências ou no seu ambiente de trabalho.

Segundo Verso e Pedro (2012), a entrevista é uma técnica voltada para a produção e significação da memória e analisar tal discurso possibilita compreender a percepção do sujeito através de suas falas, configurando-se como uma produção do conhecimento empírico.

A interpretação dos dados da pesquisa foi por meio do Método de interpretação de sentidos (MINAYO; GOMES, 2011), no qual foram analisadas as palavras e ações, assim como o conjunto de interrelações, de forma que os objetivos norteadores da pesquisa foram alcançados a partir da compreensão, interpretação e crítica da realidade do sujeito.

A observação participante foi realizada durante as reuniões do conselho, em grupos de trabalhos e câmara técnicas, permitindo que o pesquisador vivenciasse o conselho, suas ações e diálogos, propiciando uma ampla reflexão sobre o conselho, assim como, a respeito do papel, representação e responsabilidades dos conselheiros.

Cavedon (1999) sugere que o uso da observação participante ocorra a partir da imersão do pesquisador no cotidiano de uma determinada cultura, sendo somente através desse processo que se consegue compreender o universo sociocultural e o sujeito de pesquisa.

Em virtude dos aspectos legais, o referido estudo foi aprovado pelo Comitê de Ética em Pesquisa (CEP) da Universidade federal da Paraíba - UFPB, por meio do parecer de $\mathrm{n}^{\mathrm{o}}$ 2.357.719. As entrevistas foram realizadas após a leitura e assinatura do Termo de Consentimento Livre e Esclarecido (TCLE), obedecendo os procedimentos estabelecidos na resolução $n^{0}$ 466/12 do Conselho Nacional de Saúde (CNS, 2013).

\section{RESULTADOS E DISCUSSÕES}

A APA da Barra do Rio Mamanguape teve seu conselho consultivo instituído em 25 de maio de 2005, por meio da Portaria do Instituto Brasileiro do Meio Ambiente e dos Recursos Naturais Renováveis (IBAMA) $\mathrm{N}^{\circ} 34$ e tem por finalidade "auxiliar o Instituto Chico Mendes de Conservação e Biodiversidade (ICMBIO), no que concerne à administração da APA da Barra do Rio Mamanguape implementando políticas ambientais adotada para as Áreas de Proteção Ambiental Federais, visando a preservação, a conservação e o uso sustentável dos recursos naturais" (BRASIL, 2005, Art. ${ }^{\circ}$ ).
A criação do conselho consultivo da ARIE Manguezais da Foz do Rio Mamanguape, ocorreu em 2 de maio de 2013, por meio da Portaria do ICMBIO $n^{\circ} 185$. O referido conselho é formado por 24 representantes titulares, dos quis 14 pertencem ao seguimento poder público e 10 do seguimento sociedade civil e tem como função "contribuir para o efetivo cumprimento dos objetivos de criação e implementação do plano de manejo da unidade" (BRASIL, 2013, Art. $1^{\circ}$ ).

O conselho consultivo que atua em função da APA e ARIE é formado pelos 27 representantes titulares da APA da Barra do Rio Mamanguape, uma vez que são os mesmos representantes do conselho da ARIE acrescido por 3 novos conselheiros. Assim, temos 15 representantes que compõem o segmento poder público e 12 integrantes do segmento sociedade civil, apresentando uma pequena disparidade (15/12).

Quando analisado a participação do ponto de vista da frequência nas assembleias do conselho foi verificado uma maior participação dos representantes do segmento poder público em comparação aos representantes do segmento sociedade civil, que se faz representado na maioria das vezes pelo setor produtivo e organizações não governamentais (ONG).

A maior participação desses dois setores acontece por várias razões, mas destaco a necessidade que eles têm de colocar suas demandas e interesses constantemente em discussão como mecanismo de resolução de conflitos. Também saliento que este grupo compreende bem a função do conselho, o seu papel e sua importância nas reuniões e nas tomadas de decisões.

O reconhecimento da intensa participação desse pequeno grupo se deve a constatação de repetidas discussões e reivindicações, assim como pelos frequentes posicionamentos feitos sempre pelas mesmas pessoas. Conforme Ribeiro et al. (2010), a constante participação de um determinado grupo pode demonstrar o limite da participação do conselho, bem como o favorecimento e/ou a relação de poder de alguns segmentos nas tomadas de decisões.

A respeito da falta de paridade verificada na composição do conselho consultivo da APA/ARIE Manguezais da Foz do Rio Mamanguape, este fato contraria o que preconiza o artigo $9^{\circ}$, inciso V da Instrução Normativa ICMBIO 09/ 2014, quando determina que os setores do Poder Público e da sociedade civil sejam definidos levando em conta a paridade, a representatividade, a equidade na participação.

A importância de um conselho consultivo paritário está na representação dos diversos setores inseridos nas UC e na sua zona de 
amortecimento, na equidade social e na qualidade da participação dos grupos mais vulneráveis. Esse ambiente heterogêneo enriquece as discussões sobre os mais variados temas, impulsiona a construção de novos saberes, expõem a realidade local e contribui na resolução de conflitos e tomadas de decisões.

Os estudos de Scardua e Bursztyn (2003) e Berkes (2009) evidenciam que mesmo conselhos paritários em sua composição podem não se mostrar representativos, visto que existem representantes comprometidos com os interesses de outros setores, demonstrando uma superposição de opiniões em favorecimento de um único setor. Esta condição foi claramente notada no conselho estudado, onde se verificou a super-representação do setor sucroalcooleiro, que tem seus interesses resguardados por quatro conselheiros de assentos diferentes. Para fortalecer a afirmação recorre-se a fala abaixo:

Claro que cada um vai defender os seus interesses, o problema é que são pessoas que estão ocupando cadeiras, mas que na verdade defendem interesses de outros e não o da cadeira que ele está ali representando. $\mathrm{Na}$ verdade, eu nunca ouvi falar um "a" a respeito da entidade que ele representa. (Conselheiro 1A).

Ainda na análise da participação do grupo em reuniões extraordinárias e assembleias entre os anos de 2013 a 2016, foi constatado que a ausência de representantes de ambos os segmentos é superior a 50\%, destacando-se aí as prefeituras e associações comunitárias.

Tendo em vista que as prefeituras dos municípios de Marcação e Baia da Traição tem $100 \%$ de falta nas reuniões e assembleias do conselho consultivo nos últimos dois anos e por ninguém saber quem seriam seus representantes, foi necessário ir as prefeituras para identificar essas pessoas. Nesse momento, verificou-se o total desconhecimento de ambas as prefeituras sobre o conselho e a respeito da UC inseridas em seu território. Scardua e Bursztyn (2003) evidenciam que ausência das prefeituras nos conselhos é um indício de que as questões ambientais ainda não são prioridades na agenda dos municípios.

Tendo em vista que as questões ambientais não devem ser tratadas individualmente e/ou exclusivamente por instituições governamentais, entende-se que as comunidades locais devem ser vistas como prioridade para se alcançar a eficiência na gestão do ambiente natural. Segundo Bowles e Gintis (2002), os atores sociais possuem relevantes informações acerca do ambiente, do comportamento, capacidade e necessidades dos usuários dos recursos ambientais.

Os entraves que impedem uma gestão ambiental participativa e compartilhada conforme Scardua e Bursztyn (2003) encontramse no comportamento centralizador e conservacionista dos órgãos ambientais, falta de corpo técnico, capacitação e treinamento, carência de recursos financeiros e de infraestrutura, ausência de instrumentos de gestão ambiental e participação social. Laschefski e Costa (2008) apontam como impasses os múltiplos interesses e as relações de poder.

Dos itens apresentados acima, foram verificados neste estudo o comportamento centralizador das chefias das UC. Destacamos as vezes que chegaram demandas da sociedade civil nas reuniões e assembleias e as chefias, no papel de presidente do conselho, não devam a devida atenção e/ou ignoravam as questões apresentadas. Um segundo momentos foi ao final de uma assembleia onde uma das chefes das UC disse que independente dos argumentos, elas (a chefe da APA e da ARIE) que tomariam a decisão. Esse comportamento além de refletir o despreparo de ambas as chefias, fragiliza e desacredita o conselho.

Outras condições que retardam o bom gerenciamento das UC é o deficiente corpo técnico das UC, que é composto por três funcionárias do ICMBIO, os recorrentes cortes de verbas feitos pelo governo Temer, que obrigaram as gestoras a fecharem as instalações do projeto peixe boi, em razão das instalações precárias e infraestrutura sucateada, a entregar o prédio onde funcionava a secretaria de ambas UC, e que igualmente dificultam a manutenção de equipamentos essenciais para o monitoramento e fiscalização nas áreas de mangue e rio.

$\mathrm{Na}$ visão dos representantes do conselho, os obstáculos que dificultam a gestão da APA e ARIE Manguezais da foz do Rio Mamanguape são: linguagem rebuscada; ineficientes veículos de informação; atratividade das pautas e temas impostos pelo ICMBIO e a resistência em incorporar algumas demandas sociais; baixa transparência nas decisões e ações da UC; falta de credibilidade do conselho e do ICMBIO; ausência do sentimento de pertencimento dos conselheiros, que gera o desinteresse dos representantes e; burocratização das reuniões.

A linguagem técnica utilizada constantemente pelas chefias nas reuniões do conselho favorece o distanciamento e a evasão de conselheiros que possuem um baixo nível de instrução, e ascende o processo de elitização do 
conselho. Baseado no conselho estudado, a palavra elite além de estar associado aos grupos financeiramente favorecidos, está também relacionada as pessoas com maior grau de instrução. Ribeiro et al. (2010), explica que a maior participação de indivíduos com elevado grau de escolaridade não é de todo negativo, uma vez que favorece positivamente as discussões e proposições de ações de gestão da unidade, por refletir um maior grau de instrução dos conselheiros, mas por outro lado, inviabiliza a participação das comunidades locais.

Pertinente aos veículos de informação utilizados entre os representantes do conselho, verificou-se que atualmente a comunicação do grupo tem melhorado em virtude do uso das redes sociais, E-mails, WhatsApp e Facebook, por exemplo.

Em relação à novas formas de comunicação do conselho com a comunidade local e transparência das informações foi sugerido pelos conselheiros o uso de rádios comunitárias, carros de som, reuniões em diferentes locais e uso das redes sociais, por serem eficientes ferramentas na propagação de informações, fazendo com que cheguem em tempo hábil às comunidades.

Embora seja função dos representantes do conselho transmitir as informações referentes às UCs para as comunidades, nenhum conselheiro considerou ser sua função fazê-lo, apesar de eles terem consciência de que é papel deles darem retorno à sociedade.

Para mim a função do conselheiro é de extensionista, nós temos que ser a extensão entre o nosso setor e a sociedade e de lá para cá também. Quais são os interesses da sociedade para com o nosso setor? Porque somente assim, nós conseguiremos o equilíbrio entre os interesses do setor privado seja qual for, e os interesses da sociedade. Se você é a ponte entre o que a sociedade quer e o que o setor privado tem a oferecer e deseja para a sociedade, tudo fica mais fácil. (Conselheiro 20A).

A importância dada à troca e o acesso à informação expõem as duas faces que a cogestão possui: a primeira, geradora de conhecimento e a segunda, fomentadora da aprendizagem social. Mais que isso, segundo Berkes (2009) e Sandström et al. (2015) trocar e acessar informação é valorizar as várias epistemologias, é unir o conhecimento ecológico local ao científico, em prol da construção de um novo saber que fundamentará as tomadas de decisão, construindo uma gestão ambiental mais igualitária, considerando os contextos ambiental, social, econômico, político e cultural.

No tocante às pautas das reuniões, os conselheiros perceberam que os temas na maioria das vezes surgiam de maneira verticalizada (impositiva), assim como as tomadas de decisão. Isso causou grande insatisfação e desinteresse do grupo, além de romper com o caráter democrático do conselho.

Os temas são praticamente impostos pelo ICMBIO. Só tem reunião inclusive quando tem pauta. [...] só o conselho para legitimar decisões que elas precisam tomar e tem medo de tomar sozinhos. Aí vai lá no conselho convence o conselho, o conselho vota em maioria nas decisões que eles teriam que tomar, e daí para frente a culpa é do conselho. Então são decisões que faz do conselho uma coisa importante para quem defende os interesses deles, enquanto o conselho fica restrito tão somente a aprovar ou reprovar determinadas propostas, e que mesmo que o conselho desaprove, ainda pode ser feito ao contrário à revelia do conselho em alguns casos. (Conselheiro 20A)

Contrapondo a postura imperiosa e/ou proativa da instituição ambiental sobre trazer os temas às pautas foi verificado que este se deve à postura passiva do conselho, como pode ser observado no discurso apresentado abaixo.

Uma das reclamações sempre foi essa, porque a pauta nunca era de interesse de todos, ou era muito fechada. Toda reunião que eu vou encaminhar o ofício, eu sempre mando e-mail antes, e agora tem o grupo de WhatsApp, eu sempre mando perguntando - alguém tem sugestão de pauta? Ninguém responde. Aí depois reclama que a gente é autoritária. Então falta interesse mesmo das pessoas. (Conselheiro 1A).

O esquivo e/ou desinteresse dos representantes sobre a gestão das UCs, permite que os órgãos ambientais continuem a exercer uma gestão ambiental centralizada, conservacionista e verticalizada. Ribeiro (2010) sugere que é necessário fazer com que os atores sociais entendam que o poder do conselho consiste na legitimidade e representatividade dos conselheiros e não no fato do mesmo ser consultivo ou deliberativo.

Berkes (2009) e Borsdorf (2013) acreditam que estruturar os espaços coletivos do ponto de vista da rede social e torná-la um campo de 
construção de conhecimento, é uma maneira de tornar o conselho mais atuante e sensível aos temas ambientais, uma vez que são provocados os princípios de cooperação e confiança entre os atores sociais, que há a promoção da aprendizagem e conscientização do grupo, que estimula o compartilhamento de objetivos e a formação de grupos coesos, assim como propicia a colaboração entre instituições e a resolução de conflitos.

No tocante à transparência das ações e informações, o Conselheiro 1A afirma que está tentando passar as informações dentro do conselho, no entanto é difícil fazê-lo em razão da (i)maturidade do conselho, como pode ser compreendida a partir deste relato.: "Tem assuntos que se a gente levar já de cara para o conselho vai gerar mais confusão que ajudar na gestão. Então a gente tem uma certa delicadeza em levar esses assuntos para o conselho." (Conselheiro 1A).

Entende-se que a maturidade do conselho está associada ao estágio de maturidade da gestão das UC. Conforme Armitage et al (2007), a maturidade de um conselho poderá ser verificada em razão das mudanças de ponto de vista, elaboração de regras e normas, nível de confiança entre o grupo, compartilhamento de poder e de conhecimento, elaboração de organizações em rede entre outros.

No campo das representações do baixo sentimento de pertencimento do conselho foram encontrados os seguintes fatores: a incerteza que alguns conselheiros têm sobre qual conselho eles pertencem; a ênfase e/ou prioridade dada as questões da APA; e a dualidade que existe no emprego da sigla APA.

Segundo relatos dos conselheiros, a dúvida que alguns conselheiros têm sobre qual conselho eles fazem parte, emergiu durante o processo de criação do conselho consultivo da APA, quando o grupo foi informado da possibilidade do conselho ser compartilhado pelas duas UCs, no entanto, a confirmação do compartilhamento não foi realizado pelo ICMBIO.

Constatou-se uma certa dualidade no emprego da sigla APA, sobretudo em relação àqueles conselheiros mais antigos, pertencentes ao segmento sociedade civil. Por vezes, a sigla APA é entendida como uma categoria de unidade de conservação, e outras apresenta um significado associado ao ICMBIO, Centro Nacional de Pesquisa e Conservação de Mamíferos Aquáticos (CMA) e Fundação Mamíferos Aquáticos (FMA).

De acordo com o regimento interno do conselho consultivo da APA/ARIE Manguezais da Foz do Rio Mamanguape o mandato do conselheiro tem duração de dois anos, e cabe as instituições do conselho após esse período indicar ou reconfirmar o nome dos seus representantes, desse modo existem conselheiros ocupam o acento da instituição desde a criação do conselho, a exemplo do representante da colônia dos pescadores e da associação Paraibana de carciniculturas e piscicultores.

No que diz respeito à compreensão sobre o que é a APA e ARIE, os entrevistados demonstraram ter o conhecimento sobre o tema. Apenas dois conselheiros do segmento sociedade civil tem seu conhecimento limitado em saber que ambas UC são áreas protegidas, mas não compreendem suas características e existem dois conselheiros que entende por APA as instituições apresentadas acima e reconhece a ARIE como área protegida.

Para falar a verdade o entendimento é tão pouco, que a gente que trabalha dentro da área nem mesmo sabe o que significa aquilo ali. A gente só sabe que tem que fazer isso e tem que fazer assim, mas detalhar o significado eu não sei. (Conselheiro 25A)

Conforme Borsdorf (2013) é fundamental que os conselheiros tenham um bom conhecimento da região e que eles estejam organizados socialmente, na intenção de desenvolver o sentimento de pertencimento, comunidade e identidade no conselho. Assim, entende-se que o conselho precisa de uma capacitação, para que o grupo internalize a concepção da APA da Barra do Rio Mamanguape e da ARIE da Foz do Rio Mamanguape. Segundo Scardua e Bursztyn (2003) capacitar os conselheiros, permite que os mesmos sejam capazes de responder as demandas da coletividade e não tão somente, aos interesses individuais, sem beneficiar e/ou dar prioridades as necessidades de alguns setores.

Referente a efetividade da governança das unidades de conservação, sua estrutura vem sendo prejudicada pelo baixa participação e frequência dos conselheiros, igualmente pelos múltiplos interesses do grupo. Vejamos o que dizem os conselheiros.

[...] falta de comprometimento, assim, o grupo que tem ali fala - eu acho que precisa disso, eu acho que falta aquilo - são de apontar o trabalho, não são de fazer [...]. Eu não os vejo como parte ativa, só passiva. (Conselheiro 1A).

[...] lá nós somos um organismo em prol dos interesses da sociedade, mas nós não 
podemos esquecer que dentro daquela colmeia cada abelhinha tem seu objetivo, interesse e função, então dentro do conselho nós não podemos desligar dos objetivos do seu setor. (Conselheiro 20A).

[...] cada entidade que está lá está representando uma categoria e um interesse, mas eu como cidadão, também conhecedor da lei, eu estava lá para contribuir. Inclusive fiquei bastante triste, porque as vezes eu via que aquilo que o conselheiro sugeria como ideia e não era acatada. (Conselheiro 24A).

Acho que muita gente se desinteressou porque marca uma reunião, conversa, aí marca outra, mas nas reuniões não dá uma coisa efetiva. Resultado é muito pouco. (Conselheiro 17A).

Por fim, quando questionados sobre o modelo de gestão praticado na APA/ARIE da Foz do Rio Mamanguape, ficou claro que a intenção é que seja participativa e compartilhada, no entanto, a efetividade desse modelo ainda não foi alcançada em virtude de todas as problemáticas apresentadas acima, somada as recorrentes mudanças de chefias, que contribui para que seu funcionamento seja interrompido e um novo processo seja iniciado.

Eu acho que a intenção de ser um processo participativo, ela é uma expectativa de todos. Só que eu acho que a gente ainda por razões diversas está aquém de ocupar esse lugar, seja de um lado porque termina a reunião cada um se volta para sua dinâmica institucional e vai tocando no sufoco do dia a dia de cada um, seja quem for. Esse momento de integração está nessas 4 horas de reunião burocrática e só. (Conselheiro 21A).

No entanto, também existem discursos que percebem a gestão totalmente top-down, onde as tomadas de decisões chegam ao conselho já definidas, não se tratando de uma instância democrática, conforme o relato do conselheiro $25 \mathrm{~A}$.

Ali a opinião é totalmente das chefes da APA, inclusive muitas vezes eu já presenciei conselheiro 22 que é uma pessoa que bate de frente e que fala tudo e muitas vezes tem sua fala menosprezada [...]. Já vi muitas vezes acontecer isso. $\mathrm{E}$ assim, o que ela quer muitas vezes consegue à força, fundamenta o que ela está querendo, mas no final o que vale é o que ela quer, e é bem claro. Quando você fala qualquer coisa que vai contra ela já diz: é o do contra [...]. (Conselheiro 25A)

Embora os assuntos relacionados às complexidades ambientais devam ser tratados de forma democrática e participativa, conforme Scardua e Bursztyn (2003), a democracia só é possível mediante participação e representatividade dos atores sociais. No entanto, Ribeiro et al. (2010) afirma que quando esse direito lhes é cerceado, a estrutura do conselho se fragiliza, perde sua legitimidade e sua representatividade.

Baseado em todos os dados apresentados anteriormente, entende-se que as principais razões que impossibilitam o alcance de uma gestão eficiente e participativa são: a) o baixo envolvimento dos conselheiros; b) os múltiplos interesses do conselho; c) o pouco ou nenhum diálogo entre conselho e comunidade e ICMBIOcomunidade; d) e a reduzida equipe técnica do ICMBIO responsável pelas unidades.

Pensando em melhorar o desempenho do conselho, os conselheiros percebem que há necessidade de uma melhor qualificação, que as pautas devam ser atrativas, que os assuntos tratados no conselho estejam mais relacionados a realidade local e não tão somente assuntos pertinentes ao trabalho das chefias das UCs. Também foi verificado que o conselho precisa se mostrar mais aberto e altruísta frente as necessidades da coletividade, mostrando à sociedade a sua importância, que o ambiente seja democrático, com relações fortes de confiança e cooperação, que se solidarize com as questões socioambientais.

\section{CONSIDERAÇÕES FINAIS}

A gestão ambiental da APA da Barra do Rio Mamanguape e da ARIE Manguezais da Foz do Rio Mamanguape encontra-se em um constante processo de construção e desconstrução da gestão participativa, resultado das recorrentes mudanças de chefias e pela interrupção das ações voltadas à gestão das unidades de conservação, provocando aos representantes do conselho a sensação de tempo e trabalho perdido.

Apesar da paridade na composição do conselho ser importante e necessária, mais relevante que isso, é tornar o conselho um espaço de diálogo e, sobretudo, de construção de saberes, cabendo aos representantes do ICMBIO deixar 
de lado a postura e o contexto hierárquico e adotarem o papel de mediadores, dentro e fora do conselho.

Tornar qualquer conselho participativo e representativo não é uma tarefa fácil e tão pouco rápida, é preciso persistência e estratégias para sensibilizar pessoas tão distintas entre si, principalmente quando o conselho se encontra desacreditado e desmotivado, como é o caso do conselho consultivo das UCs. Por mais que cheguem novos atores sociais entusiasmados e cheios de ideia em relação à dinâmica do conselho, com o tempo, muitos tendem a se voltar para seus próprios interesses, deixando de lado os interesses da coletividade e os objetivos do conselho.

Salientamos mais uma vez a importância dos gestores do ICMBIO realizarem contínuas atividades votadas para sensibilização e capacitação dos conselheiros, de maneira que todos entendam plenamente o seu papel dentro e fora do conselho. Todos os representantes do conselho devem ter sua voz, conhecimento e história de vida valorizados, assim eles se sentirão pertencentes ao conselho e à unidade de conservação.

Os representantes do conselho precisam conhecer as unidades de conservação, tanto no que diz respeito ao aspecto jurídico, quanto físico. Perceber a APA e a ARIE do ponto de vista jurídico permitirá ao conselheiro conhecer as peculiaridades de cada unidade de conservação, seus possíveis usos, assim como as normas e leis que regem esse ambiente e conhecer fisicamente as UC dará ao conselheiro uma visão real da região. A realização de reuniões em diferentes comunidades seria uma forma eficiente de mostrar a realidade local aos representantes do conselho e de aproximar os residentes e usuários da gestão da APA e ARIE. Essa aproximação é essencial na construção da relação de confiança entre as chefias das unidades e os comunitários, resultando na maior integração e envolvimentos das comunidades na preservação dos recursos ambientais. Pensando em tornar a gestão compartilhada, é sugerido que as reuniões nas comunidades sejam organizadas pelos representantes do conselho, cabendo a eles determinar o local, um tema de interesse da comunidade para ser incluído na pauta e realizar convite aos comunitários. Caberá ao conselho apoiar o conselheiro que estará promovendo a reunião quando solicitado. Esse será um marco na promoção da organização social, do empoderamento e integração dos membros do conselho.

Por fim, entende-se que a gestão da APA/ARIE Manguezais da Foz do Rio
Mamanguape é participativa, em razão da existência do conselho consultivo. No entanto, quando se analisa a estrutura do conselho, depara-se com uma instância imatura, sem identidade, desorganizada e, por vezes, egocêntrica, resultado da baixa participação e coesão do grupo.

Em virtude da baixa autonomia do conselho, percebe-se a prática da gestão compartilhada muito distante da realidade da governança das unidades de conservação aqui estudadas.

\section{REFERÊNCIAS}

ARMITAGE, D.; BERKES, F.; DOUBLEDAY, N. (Ed.). Adaptative co-management. University of British Columbia Press, Vancouver, 2007. Disponível em: $<$ https://www.ubcpress.ca/asset/9067/1/97807 74813839.pdf> Acesso em: 1 de abril de 2015.

BERKES, F. Evolution of co-management: role of knowledge generation, bridging organizations, and social learning. Journal of Environmental Management, v.90, p. 16921702 ,

2009. https://doi.org/10.1016/j.jenvman.2008.12.001

BORSDORF, F. F. El capital social como recurso de innovación para la gestión regional em grandes áreas protegidas: La reserva de la biosfera Grobes Walsertal. Revista de Geografía Norte Grande, v. 55, p.55-66, 2013. Disponível em: $<$ https://scielo.conicyt.cl/pdf/rgeong/n55/art05. pdf > Acesso em: 14 de março de 2016

BOWLES, S.; GINTIS, H. Social capital and community governance. The Economic Journal, Oxford, v.112, p. F419-F436, nov.2002. Disponível em: $<$ http://www.umass.edu/preferen/gintis/soccap ej.pdf> Acesso em: 10 de junho de 2016

BRASIL. Lei $\mathrm{n}^{\circ} \mathbf{6 . 9 3 8}$, de 31 de agosto de $1981 . \quad$ Disponível em: <http://www.planalto.gov.br/ccivil_03/LEIS/L 6938.htm> Acesso em: 19 de fevereiro de 2015.

BRASIL. Decreto-Lei $\mathbf{n}^{\circ} 91.890$, de 05 de novembro de 1985. Disponível em: $<$ http://www.icmbio.gov.br/portal/images/stori es/imgs-unidades-

coservacao/arie_mamanguape.pdf> Acesso em: 19 de fevereiro de 2015.

BRASIL. Constituição da República Federativa do Brasil de 1988. Disponível em:

$<$ http://www.planalto.gov.br/ccivil_03/constitu icao/constituicao.htm> Acesso em: 19 de 
fevereiro de 2015 .

BRASIL. Decreto $\mathrm{n}^{\circ}$ 924, de 10 de setembro de 1993. Disponível em: <http://www.planalto.gov.br/ccivil_03/decreto/ 1990-1994/D0924.htm> Acesso em: 19 de fevereiro de 2015.

BRASIL. Decreto-Lei no 9.985, de 18 de julho de 2000. Disponível em: $<$ http://www.planalto.gov.br/ccivil_03/LEIS/L 9985.htm> Acesso em: 04 de maio de 2012.

BRASIL. Decreto $n^{\circ} 4.340$, de 22 de agosto de $2002 . \quad$ Disponível em: <http://www.planalto.gov.br/ccivil_03/decreto/ 2002/D4340.htm> Acesso em: 04 de maio de 2012.

BRASIL. Portaria $\mathbf{n}^{\mathbf{0}} \mathbf{3 4}$, de 25 de maio de 2005. Disponível em: $<$ http://www.icmbio.gov.br/portal/images/stori es/imgs-unidades-

coservacao/portarias/Apa $\% 20 \% 20$ Barra $\% 20$ do \%20Rio\%20Mamanguape\%20Port\%2034\%202 5\%2005\%202005.pdf> Acesso em: 19 de fevereiro de 2015.

BRASIL. Portaria $n^{\circ} 185$, de 2 de maio de $2013 . \quad$ Disponível em: $<$ http://www.icmbio.gov.br/portal/images/stori es/imgs-unidades-

coservacao/portarias/arie_manguezais_da_foz _do_rio_mamanguape.pdf > Acesso em: 19 de fevereiro de 2015.

BRASIL. Instrução Normativa $n^{\circ} 09$, de 05 de dezembro de 2014. Disponível em: $<$ http://www.icmbio.gov.br/cepsul/images/stori es/legislacao/Instrucao_normativa/2014/in_ic mbio_09_2014_diretrizes_modifica\%C3\%A7\% C3\%A3o_conselhos_gestores_und_conserva\% C3\%A7\%C3\%A3o_federais.pdf> Acesso em: 19 de fevereiro de 2015.

CÂMARA, J. B. D. Governança Ambiental no Brasil: ecos do passado. Revista de Sociologia e Política, v.21, n.46, p.125-146, 2013. http://dx.doi.org/10.1590/S010444782013000200008

CAVEDON, N. R. O método etnográfico em estudos sobre a cultura organizacional: implicações positivas e negativas. ANPAD, $1999 . \quad$ Disponível em: $<$ http://www.anpad.org.br/admin/pdf/enanpad 1999-org-08.pdf> Acesso em: 13 de janeiro de 2015.

ICMBIO. Plano de manejo da APA da Barra de Mamanguape e ARIE Manguezais da Foz do Rio Mamanguape. Brasília, 2014.

JACOBI, P. R. Espaços públicos e práticas participativas na gestão do meio ambiente no Brasil. Sociedade e Estado, Brasília, v.18, n.1/2, p.315-338,2003. http://dx.doi.org/10.1590/S0102-
69922003000100015

LASCHEFSKI, K.; COSTA, H.S.M. Segregação social como externalização de conflitos ambientais: a elitização do meio ambiente na APA-SUL. Região Metropolitana de Belo Horizonte. Ambiente e Sociedade, Campinas, v.11, n.2, 2008. http://dx.doi.org/10.1590/S1414753X2008000200007

MAGALHÃES, H.; BONONI, V. L. R.; MERCANTE, M. A. Participação da sociedade civil na gestão de unidades de conservação e seus efeitos na melhoria da qualidade ambiental da região sudeste do estado do Mato Grosso do Sul. Acta Scientiarum. Human and Social Sciences, Maringá, v.32, n.2, p. 183- 192, 2010.

https://doi.org/10.4025/actascihumansoc.v32i2 .6761

MINAYO, M. C. S.; GOMES, S. F. D. R. (Org.) Pesquisa social: teoria, método e criatividade. 30 ed. Petrópolis: Vozes, 2011. (Coleção Temas Sociais).

QUADROS, J.; GIRALDI-COSTA, A. C.; SEZERINO, F. S.; SANTOS, P. A. Participação social na criação e implementação de unidades de conservação no Brasil: o caso do Parque Nacional de Saint-Hilaire/Lange. Sustentabilidade em debate, Brasília, v.6, n.3, p.32-49, 2015. https://doi.org/10.18472/SustDeb.v6n3.2015.1 6318

RIBEIRO, S. C.; BARBOSA, C. S.; LOMONT, M. Avaliação da efetividade da gestão participativa na APA da Serra da Mantiqueira. Geo. UFRJ, v.1, n.21, 2010. https://doi.org/10.12957/geouerj.2010.1460

SANDSTRÖM, A.; BODIN, O.; CRONA, B. Network governance from the top - the case oh ecosystem- based coastal end marine management. Marine Policy, v. 55, p. 57-63, 2015. https://doi.org/10.1016/j.marpol.2015.01.009

SCARDUA, F. P.; BURSZTYN, M. A. A. Descentralização da política ambiental no Brasil. Sociedade e Estado. Brasília, v.18, n.1/2, 2003. Disponível em: $<$ http://www.scielo.br/pdf/se/v18n12/v18n1a13.pdf> Acesso em: 20 de fevereiro de 2016.

VERSO, A. M.; PEDRO, J. M. Memória como fonte de pesquisa em história e antropologia. Revista História Oral, v.15, n.2, p. 125-139, 2012. Disponível em: $<$ http://revista.historiaoral.org.br/index.php?j ournal $=$ rho\&page $=$ article \&op $=$ view $\&$ path $\% 5$ 
B\%5D=261\&path $\% 5 B \% 5 D=293>$ Acesso em:

16 de maio de 2013 